contemporary social and economic backgrounds. This is seconded by an able essay from Dr. H. J. Muller, who is well known as a geneticist, now of Edinburgh, entitled "The Dominance of Economics over Eugenics" in which the relationship of social systems to human inheritance, and the true value of eugenic hopes, are discussed. He propounds the question whether the present social systems of western Europe do not involve a selection of socially inferior rather than of socially superior human material. These contributions should be of interest not only to all biologists, but also to much wider circles. Fact is edited by Mr. R. W. Postgate; Mr. H. G. Wells has recently joined its editorial board.

\section{Standards on Electronics and Radio Receivers}

The Institute of Radio Engineers (330 West 42nd Street, New York) was founded in 1912 to advance the theory and practice of radio and allied branches of engineering and to maintain a high professional standard amongst its members. Although dominantly in the United States of America, the Institute membership of more than 5,000 persons is distributed throughout the world. The Proceedings, published since 1913, is issued monthly and contains contributions from leading workers in the theoretical and practical fields of radio communication. It has co-operated with many other bodies in the establishment of standards. It has published many reports dealing with the definitions of terms, letter and graphical symbols, and methods of testing and rating equipment. Now it has issued "Standards on Electronics, 1938" and "Standards on Radio Receivers, 1938" (price 50 cents each). The committees which drew up the pamphlets are to be congratulated on the thorough way they have done their work. Every radio engineer and teacher of technical electricity should have a copy of these pamphlets, for they are most useful for reference.

\section{Interplanetary Travel}

$W_{\mathrm{E}}$ have received vol. 5, No. 1 of the Journal of the British Interplanetary Society, a body "founded for the stimulation of public interest in the possibility of interplanetary travel, the dissemination of knowledge concerning the problems which the epockmaking [sic] achievement of an extra-terrestrial voyage involves, and the conducting of practical research in connection with such problems". This number of the Journal contains designs for a "space ship" intended to perform a voyage to the moon and back. While we may invite the charge of obstructionism if we dismiss the whole affair as a wild-cat speculation, it is necessary for us to remark that, while the ratio of research results accomplished to speculative theorizing is so low, little confidence can be placed in the deliberations of the British Interplanetary Society.

\section{The Midwifery Service}

THe annual report of the Central Midwives Board or the year ended March 31, 1938, has been issued (London: H.M. Stationery Office. 4d. net). At the end of the year, there were 67,089 women on the midwives roll, a net increase of 2,043 on the total for the previous year, but only a little more than a quarter of the total number of those on the roll are engaged in the practice of their profession. The number of candidates entering for the examination was 4,420 , the highest number ever recorded, of whom three quarters were successful. The report sets out the arrangements made by the Board for the approval of institutions, lecturers and teachers under the rules, of which a detailed explanation is given.

\section{Science Abstracts}

Nerther science nor industry is standing still and to anyone who wishes to keep abreast of the advances made, the two sections of Science Abstracts-Physics and Electrical Engineering-are of great service. The two index numbers published in the last week of February completed the volumes for 1938. The Physics Section contains 5,081 abstracts from about half that number of publications, the average number of the abstracts being about $4 \cdot 3$ per page. The index of subjects covers 189 pages, that of apparatus 22, and the author index 65 pages. The Electrical Engineering Section has 3,622 abstracts, about $4 \cdot 6$ to a page, with a subject index of 59 pages and an author index of 31 pages. The Physics volume is thus about 10 per cent less than, and the Electrical Engineering volume about 3 per cent larger than, the volume for 1937 .

\section{British Empire Cancer Campaign}

ThE seventieth quarterly meeting of the Grand Council of the British Empire Cancer Campaign was held on April 3. The following grants were approved, making a total to date for the year 1939 of more than $£ 48,000$ : $£ 1,000$ to the North of England Branch of the Campaign for the continuation of the special short-wave investigations being carried out under the direction of Dr. F. Dickens; and $£ 160$ to Mr. E. Nevill Willmer, working at the University of Cambridge. The Council received a report regarding the joint discussions which had taken place between representatives of the Campaign, the Medical Research Council and the National Radium Commission on the subject of the installation of a cyclotron in Great Britain primarily for medical and biological investigations as affecting the cancer problem. The three bodies have now jointly agreed to refer this matter for further consideration to the Radiology Committee. A further sum of approximately $£ 6,500$ is to be allocated to meet the expenses to be incurred during the second year's working of the scheme of the Clinical Cancer Research Committee. This scheme covers an inquiry into all fresh cases of cancer in the London area, and during the first two years the results of investigations into approximately 34,000 cases will have been placed at the disposal of the Committee. Dr. J. M. Woodburn Morison has been invited to become the representative of the Campaign on the Scientific Advisory Committee of the newly amalgamated Radium Institute and Mount Vernon Hospital. 